This work was supported by research grant, Project R.G. 673, from the Division of Research Grants and Fellowships of the National Institutes of Health, U.S. Public Health Service.

Biological Laboratory,

Hugo Fricke

Cold Spring Harbor, N.Y. Jan. 12.

1 Fernau, A., and Pauli, W., Biochem. Z., 70, 426 (1915). Wels, $\mathrm{P}_{\text {., }}$ Pflügers Arch., 199, 226 (1923). Fernau, A., and Spiegel-Adolf, Mio, 43 (1935).

${ }^{2}$ Chick, H., and Martin, E., Kolloidchem. Beihefte, 5, 49 (1914). Lewis, P. S., Biochem. J., 20, 965 (1926).

Svedberg, T., and Brohult, S., Nature, 143, 938 (1939).

- Anderson, R. S., Fed. Proc., 9, 6 (1950). Kaufmann, B. P., McDonald, M. R., and Gay, H., Year Book, Carnegie Inst. Wash., 49, 173 $(1949-50)$.

\section{o-Aminophenol in Experimental Tuberculosis}

IN 1948 Okamoto $^{1}$ reported that o-aminophenol showed a tuberculostatic effect both in vitro and in vivo (in guinea pigs). He also referred to favourable progress when this drug was used clinically in pulmonary tuberculosis. In the course of a study of the chemotherapy of experimental tuberculosis, we have included $o$-aminophenol in our tests.

In vitro tests were carried out against the $H 37 R v$ strain of Mycobacterium tuberculosis var. hominis, using the floating pellicle method with serial dilutions of the drug in modified Long's medium plus 10 per cent ox serum. o-Aminophenol inhibited this strain for four weeks at a dilution of 1 in 729,000 but not at 1 in $2,187,000$.

In vivo tests were carried out with both mice and guinea pigs. 18-22-gm. male albino mice were infected intracerebrally with $0.05 \mathrm{ml}$. of an undiluted 10-day old Kirchner 'T'ween-albumin culture of the Ravenel strain of bovine tubercle bacilli. Treatment was commenced two days after infection and continued until the twenty-third day. All the surviving mice were killed twenty-eight days after infection. The extent of tuberculosis was assessed by the macroscopic extent of lung lesions using an arbitrary scale of $0-6$.

500 -gm. guinea pigs were infected intraperitoneally with $0.25 \mathrm{ml}$. of a 1 in 100 dilution of a 14-day old Tween - albumin culture of the H418 strain of human tubercle bacilli. Drug treatment was commenced twenty-one days after infection when all pigs were tuberculin positive, and continued for sixty days,

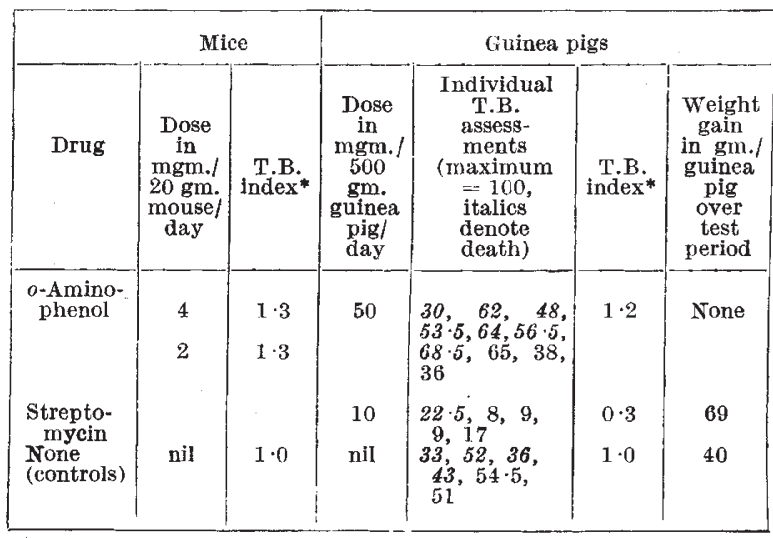

*T.B. index $=$ average T.B. assessment of drug-treated group divided by average assessment of untreated control group. when all survivors were killed. The extent of infection was assessed by the method of Sher and Kloeck ${ }^{2}$; survival times and weight changes were also recorded. Streptomycin was used as an active drug control.

The drug dosages are shown in the table, together with the results. Both drugs were given subcutaneously in two doses (a.m. and p.m.) on five days a week. The $o$-aminophenol was given in water warmed to effect solution; streptomycin was given in saline.

The results in both mice and guinea pigs indicate that $o$-aminophenol caused no retardation of tuberculosis, although high in vitro activity was confirmed. There was macroscopic evidence of tissue damage at the site of injection of $o$-aminophenol in both animals. This did not occur with streptomycin.

I wish to thank Sir Jack Drummond and Mr. C. E. Coulthard for their interest in this work, and Mr. D. E. Williamson and Mr. L. Draper for help with the animal work.

Research Department,

Bacteriology Division,

Boots Pure Drug Co., Ltd., Oakfields Road,

West Bridgford,

Nottingham Jan. 11.

${ }^{1}$ Okamoto, H., Japanese Med. J., 1, 422 (1948).

'Sher R. C., and Kloeek, J. M., Amer. Rev. Tuberc., 53, 250 (1946).

\section{Isolation of Methoxy- and 2 : 6-Dimethoxy-p-} benzoquinone from Fermented Wheat Germ

THE addition of wheat germ to flour lowers its baking quality, as is at once obvious from the smaller volume of the loaf. Hullett ${ }^{1}$ and Hullett and Stern ${ }^{2}$ found that if the wheat germ is first fermented sufficiently with yeast, there is no fall in bread quality, and this coincides with the disappearance of the glutathione. Vuataz $^{3}$ has shown that the latter is due to combination of the glutathione with one of the fermentation products, which he isolated as a yellow crystalline compound, melting point $141-143^{\circ}$ (decomp.) (I), and which he suggested was the unknown furfuryl glyoxal, $\mathrm{C}_{4} \mathrm{H}_{3} \mathrm{O}$. $\mathrm{CH}_{2}$.CO.CHO. During the isolation of this compound, a small amount of another substance, melting point $244-245^{\circ}$ (decomp.) (II), was obtained. This did not react, however, with glutathione.

In December last, Dr. E. W. Hullett, director of the Wheat Research Institute, New Zealand, was in England, and directed the attention of one of us (T.M.) to this paper by Vuataz and the light it threw on his own earlier work. As a result, following a disoussion with Dr. Hullett and Dr. E. Marsden, scientific adviser to the New Zealand Government, it was agreed that these laboratories should make a close study of substance (I) ; apart from its scientific interest, it was felt that such a study might possibly lead to developments in the field of flour improvers.

We have now repeated the isolation of these substances, using a slight modification of Vuataz's method, and have obtained similar yields of $I$ and II, 0.05 per cent and 0.01 per cent respectively of the weight of germ. Our chemical and spəctroscopic evidence does not, however, confirm the structure he suggested for $(\mathbf{I})$. We find that it is methoxy-pbenzoquinone, melting point $143-144^{\circ}$, whereas (II) is $2: 6$-dimothoxy-p-benzaquinone, molting point 